\title{
A PCR-based diagnostic assay for detecting DNA of the olive fruit fly, Bactrocera oleae, in the gut of soil-living arthropods
}

\author{
M. Rejili ${ }^{1}+\ddagger$, T. Fernandes ${ }^{1}$ t, A.M. Dinis ${ }^{2}$, J.A. Pereira ${ }^{2}$, \\ P. Baptista ${ }^{2}$, S.A.P. Santos ${ }^{2}$ and T. Lino-Neto ${ }^{1 *}$ \\ ${ }^{1}$ BioSystems and Integrative Sciences Institute (BioISI), Plant Functional \\ Biology Centre, University of Minho, Campus de Gualtar, 4710-057 Braga, \\ Portugal: ${ }^{2} \mathrm{CIMO} / \mathrm{School}$ of Agriculture, Polytechnic Institute of Bragança, \\ Campus de Santa Apolónia, 5300-253 Bragança, Portugal
}

\begin{abstract}
Bactrocera oleae (Rossi) (Diptera: Tephritidae) is considered the most devastating pest of the olive tree worldwide. In an effort to develop management and biological control strategies against this pest, new molecular tools are urgently needed. In this study, we present the design of $B$. oleae-specific primers based on mitochondrial DNA sequences of cytochrome oxidase subunit I (COI) gene. Two pairs of B. oleae-specific primers were successfully designed and named as SBo1-F/SBo1-R and SBo2-F/ SBo1-R, being able to amplify 108 and 214 bp COI fragments, respectively. The specificity of designed primers was tested by amplifying DNA from phylogenetically related (i.e. Diptera order) and other non-pest insects living in olive groves from the Mediterranean region. When using these primers on a PCR-based diagnostic assay, B. oleae DNA was detected in the gut content of a soil-living insect, Pterostichus globosus (Fabricius) (Coleoptera: Carabidae). The detection of B. oleae DNA in the guts of arthropods was further optimized by adding bovine serum albumin enhancer to the PCR reaction, in order to get a fast, reproducible and sensitive tool for detecting $B$. oleae remains in the guts of soil-living arthropods. This molecular tool could be useful for understanding pest-predator relationships and establishing future biological control strategies for this pest.
\end{abstract}

Keywords: Bactrocera oleae, specific primers, diagnostic PCR, feeding assay

(Accepted 25 May 2016)

*Author for correspondence

Phone: +351 253601544

Fax: +351 253678980

E-mail: tlneto@bio.uminho.pt

tThese authors contributed equally to this work.

$\ddagger$ Permanent address: Faculty of Sciences, Research Unit Biodiversity and Valorization of Arid Areas Bioresources (BVBAA), Gabès University, Erriadh-Zrig, 6072 Gabès, Tunisia.

\section{Introduction}

Bactrocera oleae (Rossi) (Diptera: Tephritidae) is the most harmful olive pest worldwide. Female flies lay eggs in olive fruits, where the newly hatched larvae feed upon the pulp, reducing the quality of olives and olive oil. Larvae pupate and overwinter on the ground, and then emerge in spring as adult flies. The olive fruit fly only attacks plants of the Olea genus, and spreads quickly to nearby olive groves. There are well-reported $B$. oleae outbreaks in the Mediterranean region and other regions have been seriously affected, such as North, Central and South America, Central Asia (Augustinos et al., 2002), or East and South Africa (Copeland et al., 2004). Due to these attacks, economic losses can reach nearly 800 
million US dollars per year (Bueno \& Jones, 2002). Therefore, more efficient and safer methods for pest control are required.

For many years, the main method adopted to control this pest has been based on spraying organophosphate insecticides, which have led to the development of $B$. oleae pesticide resistance and enhancement of the risk of pest outbreaks (Bueno \& Jones, 2002; Vontas et al., 2002; Hawkes et al., 2005). More recently, there has been an increasing interest for the application of conservation biological control strategies against this pest aiming at conserving and promoting the effectiveness of $B$. oleae natural enemies and decrease the use of pesticides in olive groves. Thus, accurate identification of $B$. oleae natural enemies is required, mainly of those soil arthropods which feed on hibernating pupae and could contribute for maintaining pest density at a low level (Gariepy et al., 2007). PCR-based techniques have been valuable tools for studying trophic relationships of pest species, such as Bactrocera minax (Enderlein) and Bactrocera tsuneonis (Miyake) (Diptera: Tephritidae) (Jiang et al., 2014), Ceratitis capitata (Wiedemann) (Diptera: Tephritidae) (Monzó et al., 2010) and seven mealybug species found in vineyards (Daane et al., 2011). These tools have been also used in large-scale studies describing food webs in ecosystems (Valentini et al., 2009; Staudacher et al., 2011), as well as in biological control programmes (Agboton et al., 2009; Jenkins et al., 2012). Another helpful molecular approach is DNA barcoding that allows species identification by sequencing a standardized DNA sequence (barcode). Since animal mitochondrial DNA sequences evolve faster than nuclear DNA, they accumulate many nucleotide differences even between closely related species, which has been very useful for phylogenetic studies (e.g., Cameron, 2014). For animal identification, the most suitable barcode has been the $5^{\prime}$ end of the mitochondrial cytochrome oxidase subunit I (COI) sequence, due to the high sequence divergence found between species and at the same time the availability of conserved regions that allows the use of universal primers (Hebert et al., 2003). This molecular approach has been applied in the identification of insects, including Diptera and several primers have been designed so far for Diptera-specific PCR amplification (Gibson et al., 2011).

Taking into account future applications in ecological studies about pest-predator interactions, the main goal of this work was to design-specific primers within the COI gene to be used in a PCR-based diagnostic method for detecting B. oleae DNA. The effectiveness of such a diagnostic molecular tool was validated in this work by detecting $B$. oleae DNA in the guts of Pterostichus globosus (Fabricius) (Coleoptera: Carabidae) adults. This species is a generalist predator that has been described as one of the most abundant carabid beetles on the ground of olive groves (Dinis et al., 2016a), displaying high predatory activity on $B$. oleae pupae. In non-choice laboratory experiments, a single $P$. globosus specimen was able to ingest up to a maximum of 30 pupae in $24 \mathrm{~h}$ (Dinis et al., 2016b).

\section{Materials and methods \\ Insect collection}

Bactrocera oleae pupae were obtained from infested olive fruits collected in an olive grove (October/November 2013), while Rhagoletis cerasi (L.) (Diptera: Tephritidae) pupae were obtained from cherries collected in an orchard (June 2015), both located in Mirandela (Northeastern Portugal). Drosophila melanogaster Meigen (Diptera: Drosophilidae) pupae were obtained from a laboratory culture maintained at the University of Minho (UM). Calliphora vicina Robineau-Desvoidy (Diptera: Calliphoridae) adults were collected in the Campus of University of Minho (Portugal). Soil insect adults, including $P$. globosus specimens, were collected by hand in an organic olive grove in the region of Mirandela (Northeastern Portugal), between September of 2013 and May of 2014. All insects were initially identified to species using a binocular stereomicroscope, followed by a molecular identification using the methods described in subsection 'DNA extraction and amplification of mitochondrial COI gene'. Insects were preserved in absolute ethanol and stored at $-80^{\circ} \mathrm{C}$ to avoid deterioration of DNA.

\section{DNA extraction and amplification of mitochondrial COI gene}

For insect molecular identification and to prevent the interference of DNA from ingested preys in the gut content, genomic DNA was extracted from legs, antennae and wings of adult insects using the Ron's Tissue DNA Mini Kit (Bioron $\mathrm{GmbH}$, Germany). The barcode region of mitochondrial COI gene was amplified using the universal primers LCO1490/ UEA10 (Folmer et al., 1994; Lunt et al., 1996). The reactions were performed using the FastStart High Fidelity PCR System (Roche Diagnostics $\mathrm{GmbH}$, Germany) in a final volume of $25 \mu \mathrm{l}$ containing $1 \times$ buffer, $100 \mu \mathrm{M}$ of each dNTP, $2 \mathrm{mM}$ $\mathrm{MgCl}_{2}, 200 \mathrm{nM}$ of each primer and $0.05 \mathrm{U}$ Taq DNA polymerase. PCR was performed in a MJ Mini BioRad ${ }^{\circledR}$ thermocycler with the following protocol: preheating $\left(94^{\circ} \mathrm{C}, 5 \mathrm{~min}\right), 35 \mathrm{cy}-$ cles at $94^{\circ} \mathrm{C}$ for $60 \mathrm{~s}, 55^{\circ} \mathrm{C}$ for $60 \mathrm{~s}, 72^{\circ} \mathrm{C}$ for $90 \mathrm{~s}$, and a final extension at $72^{\circ} \mathrm{C}$ for $10 \mathrm{~min}$. PCR products ( $\sim 1500 \mathrm{bp}$ ) were run on a $1 \%(\mathrm{v} / \mathrm{v})$ agarose gel, stained with Green Safe Premium (NZYTech, Portugal) and visualized under UV light. The target amplicons were purified and sequenced (STAB VIDA sequencing services, Portugal).

\section{Design of B. oleae-specific primers and diagnostic PCR}

Primers were designed to ensure the amplification of the target sequences from $B$. oleae, while avoiding cross-reactivity. Available COI sequences for B. oleae and other insects were recovered from GenBank and Barcode of Life Data Systems databases and aligned together with $C O I$ sequence of $B$. oleae specimens collected in Mirandela, using the MegAlign program (DNASTAR, Lasergene Version 7). Two forward primers, SBo1-F (5'CAG TAG TAC TAA CAG CCC TAC T $3^{\prime}$ ) and SBo2-F (5'TTA GCA GGT ATC TCC TCA ATC 3') and one reverse primer, SBo1-R (5'CTG GGT CGA AAA AGG AAG TAT'3), were selected as $B$. oleae-specific primers. The target specificity of these primers was checked by using the Primer-BLAST tool of NCBI (http://www.ncbi.nlm.nih.gov/ tools/primer-blast).

In order to specifically detect B. oleae DNA, the PCR amplification conditions were optimized, using the designed primers and all basic components as described above (subsection 'DNA extraction and amplification of mitochondrial COI gene'). The PCR program was optimized in order to improve the specificity of primers, resulting in the following protocol: an initial preheat for $3 \mathrm{~min}$ at $94^{\circ} \mathrm{C}$, followed by 30 cycles at $94^{\circ} \mathrm{C}$ for $30 \mathrm{~s}, 60^{\circ} \mathrm{C}$ for $40 \mathrm{~s}, 72^{\circ} \mathrm{C}$ for $20 \mathrm{~s}$ and a final extension at $72^{\circ} \mathrm{C}$ for $10 \mathrm{~min}$. The use of bovine serum albumin (BSA) in the diagnostic amplification was tested by adding BSA at a final concentration of $0.5 \mu \mathrm{g} \mathrm{ll}^{-1}$ to the PCR reaction. The specificity 


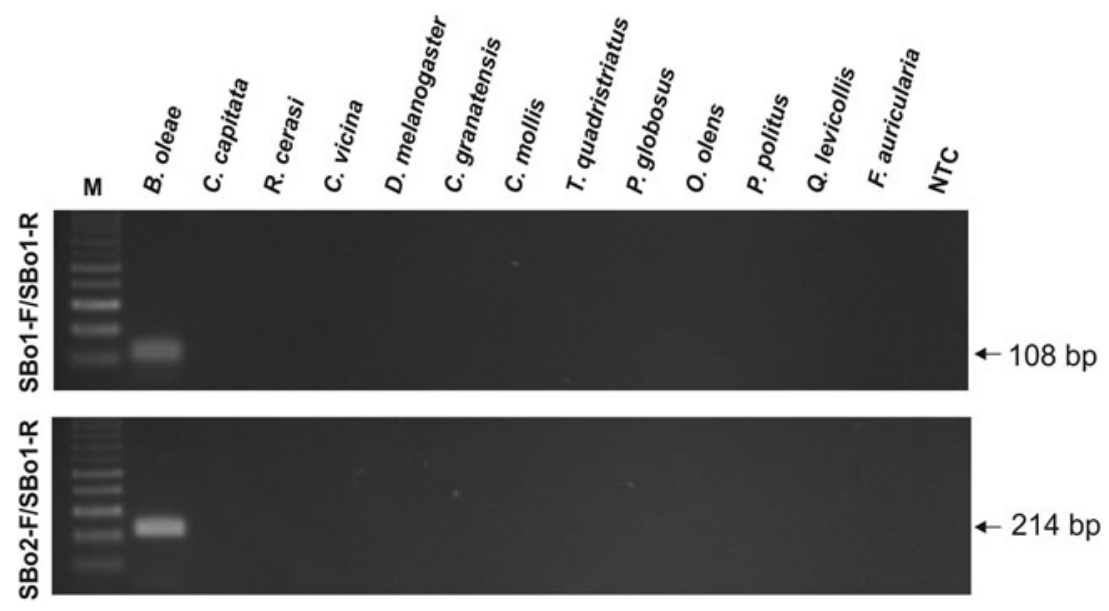

Fig. 1. Designed primers specificity for Bactrocera oleae DNA detection. Agarose gel electrophoresis of COI-amplified fragments using B. oleae-specific primer pairs SBo1-F/SBo1-R and SBo2-F/SBo1-R and template DNA from different insect species (100 or $50 \mathrm{ng}$ for each pair of primers, respectively). The selected species belong to Diptera (Tephritidae: B. oleae, Ceratitis capitata and Rhagoletis cerasi; Calliphoridae: Calliphora vicina; Drosophilidae: Drosophila melanogaster), Coleoptera (Carabidae: Calathus granatensis, Calathus mollis, Trechus quadristriatus and Pterostichus globosus; Staphylinidae: Ocypus olens, Philonthus politus and Quedius levicollis) and Dermaptera (Forficulidae: Forficula auricularia). Lane M is a $100 \mathrm{bp}$ DNA ladder and the NTC lane is a no template control.

of the primers to $B$. oleae was evaluated by using genomic DNA (50 ng) extracted from crushed pupae and from legs, antennae and wings of related dipterans and soil insects in a PCR assay, in order to ensure the exclusive amplification of the target sequence from B. oleae. The optimal concentration of gut genomic DNA to be used in diagnostic PCR was determined using DNA extracted from the guts of $P$. globosus just after they had been fed on $B$. oleae pupae at different amounts of DNA template amounts (25-150 ng). All PCR products were run on a $2 \%$ agarose gel, stained with Green Safe Premium (NZYTech, Portugal) and visualized under UV light.

\section{Feeding assay and digestion of B. oleae}

Experiments were conducted by feeding P. globosus adults on $B$. oleae pupae. First, to ensure that animals had their guts emptied, they were placed in a climate chamber at $21 \pm 1^{\circ} \mathrm{C}$, with $70 \pm 5 \%$ relative humidity, and a photoperiod of $16: 8 \mathrm{~h}$ (L:D) and starved for 7 days. Each individual was then fed on two pupae of B. oleae. After feeding, P. globosus adults were sacrificed at different periods $(0,2,4,6,8,10,16 \mathrm{~h})$ and their intestinal apparatus were removed. The genomic DNA extraction from insect guts was performed on individuals by using the Ron's Tissue DNA Mini Kit (Bioron $\mathrm{GmbH}$, Germany). DNA pools from three individuals were prepared using equal amounts of DNA and a total of three replicates were prepared. DNA concentrations were measured by a Qubit Fluorometer 3.0 (Invitrogen, USA) using the Quant-iT ${ }^{\mathrm{TM}}$ dsDNA high-sensitivity (HS) Assay Kit (Invitrogen, USA). The digestion profile of $B$. oleae was then evaluated by PCR using the designed primers and optimal concentrations, in the

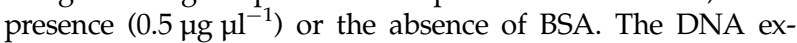
tracted from the guts of starved $P$. globosus specimens was used as negative control $\left(\mathrm{C}^{-}\right)$and $B$. oleae DNA was used as positive control $\left(\mathrm{C}^{+}\right)$. A PCR reaction without template DNA was used as no template control (NTC).

\section{Results}

For the specific detection of B. oleae DNA, primers for the variable region of the $5^{\prime}$ end of mitochondrial $C O I$ sequence were designed taking into account the specific sequence of this insect. Forty-eight available $C O I$ sequences for $B$. oleae were aligned together with $C O I$ sequences from $B$. oleae collected in Mirandela, for detecting possible nucleotide polymorphisms in COI gene among $B$. oleae sequences. The $B$. oleae conservative sequence was then aligned with 120 $\mathrm{COI}$ sequences from phylogenetically related insects. $B$. oleaespecific primers were selected by comparing the highly variable COI regions among this fruit fly and other species, while avoiding intra-specific single nucleotide polymorphisms. Primers were checked for unfavorable secondary structures and compared with other DNA sequences using a BLAST search in the NCBI database to make sure they do not hit other genomic locations in target organisms. All designed primers (SBo1-F, SBo2-F and SBo1-R) amplified $B$. oleae DNA, resulting in a single DNA fragment. The use of both pairs of primers, SBo1-F/SBo1-R and SBo1-F/ SBo2-R, generated a specific amplification with the predicted PCR products of 108 and $214 \mathrm{bp}$, respectively. Sequence analysis of amplified products indicated that both fragments shared $100 \%$ identity with B. oleae COI gene. No amplification was detected when using DNA extracted from legs, antennae and wings of other insects, which reveals the high specificity of the designed primers (fig. 1).

The efficiency of this PCR-based diagnostic test was then validated by the detection of $B$. oleae remains in the guts of a soil-living insect, $P$. globosus, as confirmed by the sequencing of the amplified fragments. Taking into account that insect guts could contain several PCR contaminants, and gut genomic DNA should be in sufficient amounts to allow the detection of even limited remains of B. oleae, the template DNA amount to be used in diagnostic PCR was optimized using insects that had just been fed on B. oleae pupae (fig. 2). The optimal DNA template amount was $100 \mathrm{ng}$ for the primers pair SBo1-F/ 


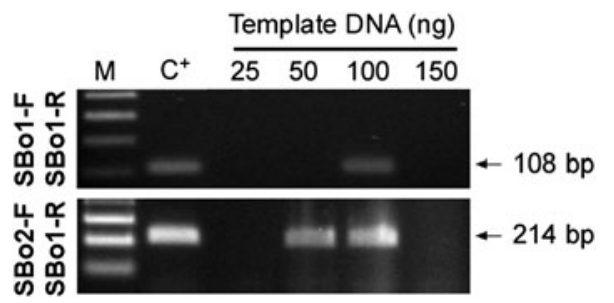

Fig. 2. Gut genomic DNA concentration optimization for detection of Bactrocera oleae DNA in feeding assay experiments. Pterostichus globosus insects just after been fed on B. oleae pupae were sacrificed and their intestinal apparatus used for genomic DNA extraction. Both B. oleae-specific primer pairs (SBo1-F/ SBo1-R and SBo2-F/SBo1-R) were used in a diagnostic PCR containing BSA $\left(0.5 \mu \mathrm{g} \mathrm{Ll}^{-1}\right)$ and different amounts of template DNA (25-150 ng). Lane $M$ is a $100 \mathrm{bp}$ DNA ladder and $\mathrm{C}^{+}$ corresponds to a positive control (B. oleae genomic DNA).

SBo1-R, but only $50 \mathrm{ng}$ for the second primers pair SBo2-F/ SBo1-R. These optimized concentrations were used in order to follow the digestion of B. oleae pupae by P. globosus using the designed diagnostic PCR. For testing the enhancer effect of BSA in amplification, all reactions were performed with and without BSA $\left(0.5 \mu \mathrm{g} \mu \mathrm{l}^{-1}\right)$. The absence of BSA affected the amplification consistency, since $B$. oleae DNA was not regularly detected in every replicate (fig. 3). This was more evident when using the primers pair SBo2-F/SBo1-R, resulting in an increased irregular amplification in replicates. Also, the feeding period where B. oleae DNA ceased to be detected in P. globosus was different in the absence of BSA for each: $10 \mathrm{~h}$ for SBo1-F/SBo1-R and $16 \mathrm{~h}$ for SBo2-F/SBo1-R (fig. 3). On the contrary, PCR amplifications performed in the presence of BSA always resulted in consistent amplifications up to the end of the feeding experiment $(16 \mathrm{~h})$.

\section{Discussion}

This study developed a new PCR-based diagnostic assay for B. oleae using specific PCR primers for the COI DNA barcode region (Hebert et al., 2003). This gene displays high variable regions among different animal species, from which species-specific primers have been designed for performing species identification (Gariepy et al., 2007). The use of COI-specific primers in diagnostic PCR has been applied with success for the identification of Bactrocera spp., such as B. minax, B. tsuneonis and B. correcta, through the amplification of DNA extracted from either part or the entire body of an adult, larva or pupa (Jiang et al., 2013, 2014). The PCR-based diagnostic assay proposed in this work, not only presented new designed primers for the successful diagnosis of $B$. oleae, even in an early stage such as the larva or pupa, but also optimizes the PCR assay for detecting $B$. oleae remains in the guts of potential soil predators, which will be very useful for describing $B$. oleae-related food webs in olive grove ecosystems. Primer's specificity was tested to detect target and non-target species, since generalist predators can feed on a wide variety of prey items in olive groves. This reduces the likelihood of getting false positives due to the cross-reactivity of primers (Admassu et al., 2006).

The feeding activity of $P$. globosus adults against $B$. oleae pupae was successfully followed by applying the conceived diagnostic PCR assay on the guts of the predator. The choice

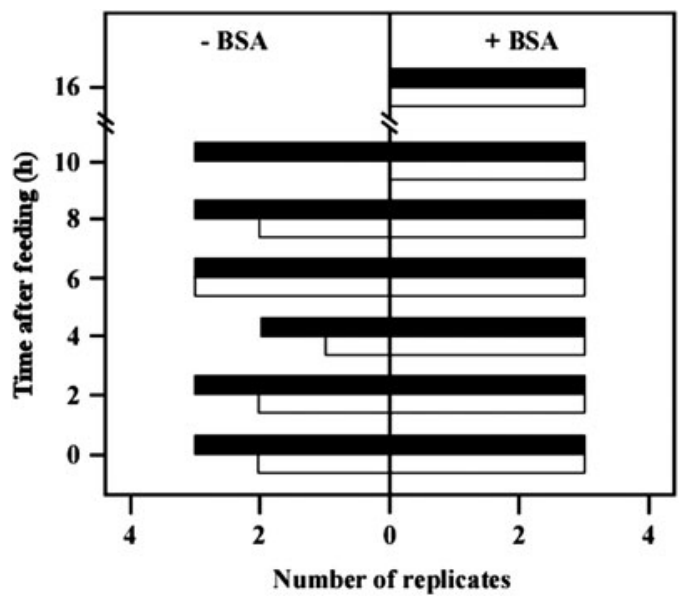

Fig. 3. BSA effect on diagnostic PCR consistency in detecting Bactrocera oleae DNA on feeding assays. The number of PCR replicates that have resulted in an amplified product are represented in columns. Pterostichus globosus adults were fed on $B$. oleae pupae, after which they were sacrificed at different digestion periods $(0-16 \mathrm{~h})$ and their intestinal apparatus used for genomic DNA extraction. Diagnostic PCR was performed using B. oleae-specific primers [SBo1-F/SBo1-R (white columns) and SBo2-F/SBo1-R (black columns)] and template DNA amount (100 ng for SBo1-F/SBo1-R primers and $50 \mathrm{ng}$ for SBo2-F/ SBo1-R primers), in PCR reactions that contained BSA $(0.5 \mu \mathrm{g}$ $\mu^{-1}$ ) or not. Three replicates of $P$. globosus gut DNA were tested at each time period $(0,2,4,6,8,10,16 \mathrm{~h})$.

of the method used for DNA extraction of this kind of sample revealed to be very important to obtain a high quality DNA for downstream analysis. Insects are very rich in polysaccharides, one of the contaminants that can inhibit the PCR reaction, especially when the goal is to check the intestinal content (Staudacher et al., 2011). The use of BSA can improve PCR amplification in samples rich in contaminants acting as a PCR enhancer (Farell \& Alexandre, 2012). When DNA was extracted from the intestinal content of $P$.g lobosus, BSA proved to increase the PCR yield in such low purity templates as the intestinal content of arthropods. BSA had an enhancer effect and should be used in these types of samples to get more accurate and robust results.

The designed B. oleae-specific primers and optimized PCR-based diagnostic assay could provide an effective, fast and inexpensive method for detecting B. oleae predators, which will help to manage a more sustainable olive production system by the future identification of potential predators of B. oleae. Further studies will be performed in order to study predation of B. oleae by soil arthropods. For olive growers, this will represent the production of high-quality olives by reducing the application of insecticides and improving ecosystem services provided by soil arthropods such as biological control of pests.

\section{Acknowledgements}

This work was supported by FEDER Funds throughout Programa Operacional Factores de Competitividade COMPETE and National Funds throughout FCT - Fundação para a Ciência e Tecnologia, within the project EXCL/ AGR-PRO/0591/2012: Olive crop protection in sustainable 
production under global climatic changes: linking ecological infrastructures to ecosystem functions. M. Rejili was supported by a fellowship on the frame of Erasmus Mundus EU MARE NOSTRUM.

\section{References}

Admassu, B., Juen, A. \& Traugott, M. (2006) Earthworm primers for DNA-based gut content analysis and their cross-reactivity in a multi-species system. Soil Biology and Biochemistry 38, 1308-1315.

Agboton, B.V., Junior, I.D., Hanna, R. \& Tiedemann, A.V. (2009) Molecular detection and differentiation of Brazilian and African isolates of the entomopathogen Neozygites tanajoae (Entomophthorales: Neozygitaceae) with PCR using specific primers. Biocontrol Science and Technology 19, 67-79.

Augustinos, A., Zacharopoulou, E., Stratikopoulos, A. \& Mathiopoulos, K. (2002) Polymorphic microsatellite markers in the olive fly, Bactrocera oleae. Molecular Ecology Notes 2, $278-280$.

Bueno, A.M. \& Jones, O. (2002) Alternative methods for controlling the olive fly, Bactrocera oleae, involving semiochemicals. IOBC WPRS Bulletin 25, 1-11.

Cameron, S.L. (2014) Insect mitochondrial genomics: implications for evolution and phylogeny. Annual Review Entomology 59, 95-117.

Copeland, R.S., White, I.M., Okumu, M., Machera, P. \& Wharton, R.A. (2004) Insects associated with fruits of the Oleaceae (Asteridae, Lamiales) in Kenya, with special reference to the Tephritidae (Diptera). Bishop Museum Bulletin in Entomology 12, 135-164.

Daane, K.M., Middleton, M.C., Sforza, R., Cooper, M.L., Walton, V.M., Walsh, D.B., Zaviezo, T. \& Almeida, R.P.P. (2011) Development of a multiplex PCR for identification of vineyard mealybugs. Environmental Entomology 40, 1595-1603.

Dinis, A.M., Pereira, J.A., Pimenta, M.C., Oliveira, J., BenhadiMarín, J. \& Santos, S.A. (2016a) Suppression of Bactrocera oleae (Diptera: Tephritidae) pupae by soil arthropods in the olive grove. Journal of Applied Entomology. doi: 10.1111/jen.12291.

Dinis, A.M., Pereira, J.A., Benhadi-Marín, J. \& Santos, S.A.P. (2016b) Feeding preferences and functional responses of Calathus granatensis and Pterostichus globosus (Coleoptera: Carabidae) on pupae of Bactrocera oleae (Diptera: Tephritidae). Bulletin of Entomological Research. doi: 10.1017/ S0007485316000213.

Farell, E.M. \& Alexandre, G. (2012) Bovine serum albumin further enhances the effects of organic solvents on increased yield of polymerase chain reaction of GC-rich templates. BMC Research Notes 5, 257.

Folmer, O., Black, M., Hoeh, W., Lutz, R. \& Vrijenhoek, R. (1994) DNA primers for amplification of mitochondrial cytochrome c oxidase subunit I from diverse metazoan invertebrates. Molecular Marine Biology and Biotechnology 3, 294-299.
Gariepy, T.D., Kuhlmann, U., Gillott, C. \& Erlandson, M. (2007) Parasitoids, predators and PCR: the use of diagnostic molecular markers in biological control of arthropods. Journal of Applied Entomology 131, 225-240.

Gibson, J.F., Kelso, S., Jackson, M.D., Kits, J.H., Miranda, G.F.G. \& Skevington, J.H. (2011) Diptera-specific polymerase chain reaction amplification primers of use in molecular phylogenetic research. Annals of the Entomological Society of America 104, 976-997.

Hawkes, N.J., Janes, R.W., Hemingway, J. \& Vontas, J. (2005) Detection of resistance-associated point mutations of organophosphate-insensitive acetylcholinesterase in the olive fruit fly, Bactrocera oleae (Gmelin). Pesticide Biochemistry and Physiology 81, 154-163.

Hebert, P.D.N., Cywinska, A., Ball, S.L. \& DeWaard, J.R. (2003) Biological identifications through DNA barcodes. Proceedings of the Royal Society B: Biological Sciences 270, 313-321.

Jenkins, C., Chapman, T.A., Micallef, J.L. \& Reynolds, O.L. (2012) Molecular techniques for the detection and differentiation of host and parasitoid species and the implications for fruit fly management. Insects 3, 763-788.

Jiang, F., Li, Z.H., Deng, Y.L., Wu, J.J., Liu, R.S. \& Buahom, N. (2013) Rapid diagnosis of the economically important fruit fly, Bactrocera correcta (Diptera: Tephritidae) based on a species-specific barcoding cytochrome oxidase I marker. Bulletin of Entomological Research 103, 363-371.

Jiang, F., Li, Z.H., Wu, J.J., Wang, F.X. \& Xiong, H.L. (2014) A rapid diagnostic tool for two species of Tetradacus (Diptera: Tephritidae: Bactrocera) based on species-specific PCR. Journal of Applied Entomology 138, 418-422.

Lunt, D.H., Zhang, D.X., Szymura, J.M. \& Hewitt, G.M. (1996) The insect cytochrome oxidase I gene: evolutionary patterns and conserved primers for phylogenetic studies. Insect Molecular Biology 5, 153-165.

Monzó, C., Sabater-Muñoz, B., Urbaneja, A. \& Castañera, P. (2010) Tracking medfly predation by the wolf spider, Pardosa cribata Simon, in citrus orchards using PCR-based gut-content analysis. Bulletin of Entomological Research 100, $145-152$.

Staudacher, K., Wallinger, C., Schallhart, N. \& Traugott, M. (2011) Detecting ingested plant DNA in soil-living insect larvae. Soil Biology and Biochemistry 43, 346-350.

Vontas, J.G., Hejazi, M.J., Hawkes, N.J., Cosmidis, N., Loukas, M. \& Hemingway, J. (2002) Resistance-associated point mutations of organophosphate insensitive acetylcholinesterase, in the olive fruit fly Bactrocera oleae. Insect Molecular Biology 11, 329-336.

Valentini, A., Miquel, C., Nawaz, M.A., Bellemain, E.V.A., Coissac, E., Pompanon, F., Gielly, L., Cruaud, C., Nascetti, G., Wincker, P., Swenson, J.E. \& Taberlet, P. (2009) New perspectives in diet analysis based on DNA barcoding and parallel pyrosequencing: the trnL approach. Molecular Ecology Resources 9, 51-60. 